\title{
BMJ Open Is healthy children surveillance being duplicated by family physicians and paediatricians? A cross-sectional study in Portugal
}

Susana Rebelo, ${ }^{1}$ Sofia Velho Rua, ${ }^{1}$ Joana d'Orey Leça, ${ }^{2}$ Ana Couto, ${ }^{3}$ Rute Teixeira, ${ }^{4}$ João Firmino-Machado ${ }^{5,6}$

To cite: Rebelo S, Velho Rua S, d'Orey Leça J, et al. Is healthy children surveillance being duplicated by family physicians and paediatricians? A cross-sectional study in Portugal. BMJ Open 2018;8:e015902. doi:10.1136/ bmjopen-2017-015902

- Prepublication history and additional material for this paper are available online. To view these files, please visit the journal online (http://dx.doi. org/10.1136/bmjopen-2017015902).

SVR and J'OL contributed equally.

Received 10 January 2017 Revised 2 January 2018 Accepted 12 January 2018
Check for updates

For numbered affiliations see end of article.

\section{Correspondence to} Dr João Firmino-Machado; firmino.firminomachado@gmail. com

\section{ABSTRACT}

Objectives To determine if children attend the family physician (FP) or the FP/paediatrician for their surveillance medical appointments, as well as analyse the variables associated with the parents' choice between the two physicians.

Design Cross-sectional study.

Setting Public, semiprivate and private kindergartens in the city of Vila Nova de Famalicão (Portugal).

Participants Parents of children aged 6 years or less without chronic diseases, enrolled in the selected kindergartens.

Main outcome measures Proportion of children attending the FP or FP/paediatrician for their surveillance appointments; association between the chosen physician and sociodemographic and household variables (parents' age, educational level, professional situation and marital status; household net income; number of children; the child's age; presence of private health insurance), assessment of the parents' perception of clinical knowledge and accessibility regarding the FP and the paediatrician.

Results A total of 697 children were included in the analysis: $30.6 \%$ attended only the FP and $69.4 \%$ attended both the FP and the paediatrician. Using a Poisson regression, the mother's age ( $P R=1.02,95 \% \mathrm{Cl} 1.00$ to $1.03)$, higher educational level (prevalence ratio $(P R=1.15$, $95 \% \mathrm{Cl} 1.00$ to 1.33), private health insurance ( $\mathrm{PR}=1.30$, $95 \% \mathrm{Cl} 1.15$ to 1.46 ), number of children ( $\mathrm{PR}=0.86,95 \% \mathrm{Cl}$ 0.78 to 0.94 ) and the child's age ( $P R=0.95,95 \% \mathrm{Cl} 0.91$ to 0.98 ) were statistically associated with attending both the FP and the paediatrician; parents of children who attended only FP rated the FP with a higher accessibility and knowledge mean score than those who consulted both physicians (2.91vs2.38, $\mathrm{P}<0.001$, and 4.11vs3.85, $\mathrm{P}<0.001$ ).

Conclusions Our data show that $70 \%$ of our sample simultaneously attended an FP and a paediatrician. FPs are equally qualified to provide medical care to healthy children but this information is not properly transmitted to the general population.

\section{INTRODUCTION}

According to the Robert Graham Center in the USA, the ratio of children's
Strengths and limitations of this study

To our knowledge, this was the first study addressing the factors associated with parents' choice in the medical care of their children.

- Our study has an adequate sampling, taking into consideration the three existing school types: public, semiprivate and private.

- The conclusions of our study may be valid in other settings since the population includes children from different social backgrounds and ages.

- We could only determine the variables associated with attending the FP or the paediatrician, but not the causes of this decision.

healthcare provided by family physicians (FPs) decreased by about 33\% between 1992 and 2002, from one in four children to one in six. ${ }^{12}$ At the same time, there was an increase in the number of visits to paediatricians. FPs provide care to approximately $20 \%$ of children between birth and 5 years of age, and this proportion increases to nearly $50 \%$ for adolescents, compared with $78 \%$ and $44 \%$, respectively, in the case of the paediatricians. ${ }^{1}$

FPs located in rural and suburban areas are more likely to provide care to children than those in areas with a higher density of paediatricians. ${ }^{23}$ Children who do not have health insurance or public health insurance are also more likely to go to FPs. ${ }^{1}$ Regarding the physician's characteristics, younger age and female sex are positively correlated with medical care being provided by FPs. ${ }^{3}$

Currently, the Portuguese healthcare system is characterised by two coexisting systems: the public universal National Health Service (NHS) and the private sector. The latter includes private insurance schemes for certain professions (health subsystems) and voluntary health insurance. People can also 

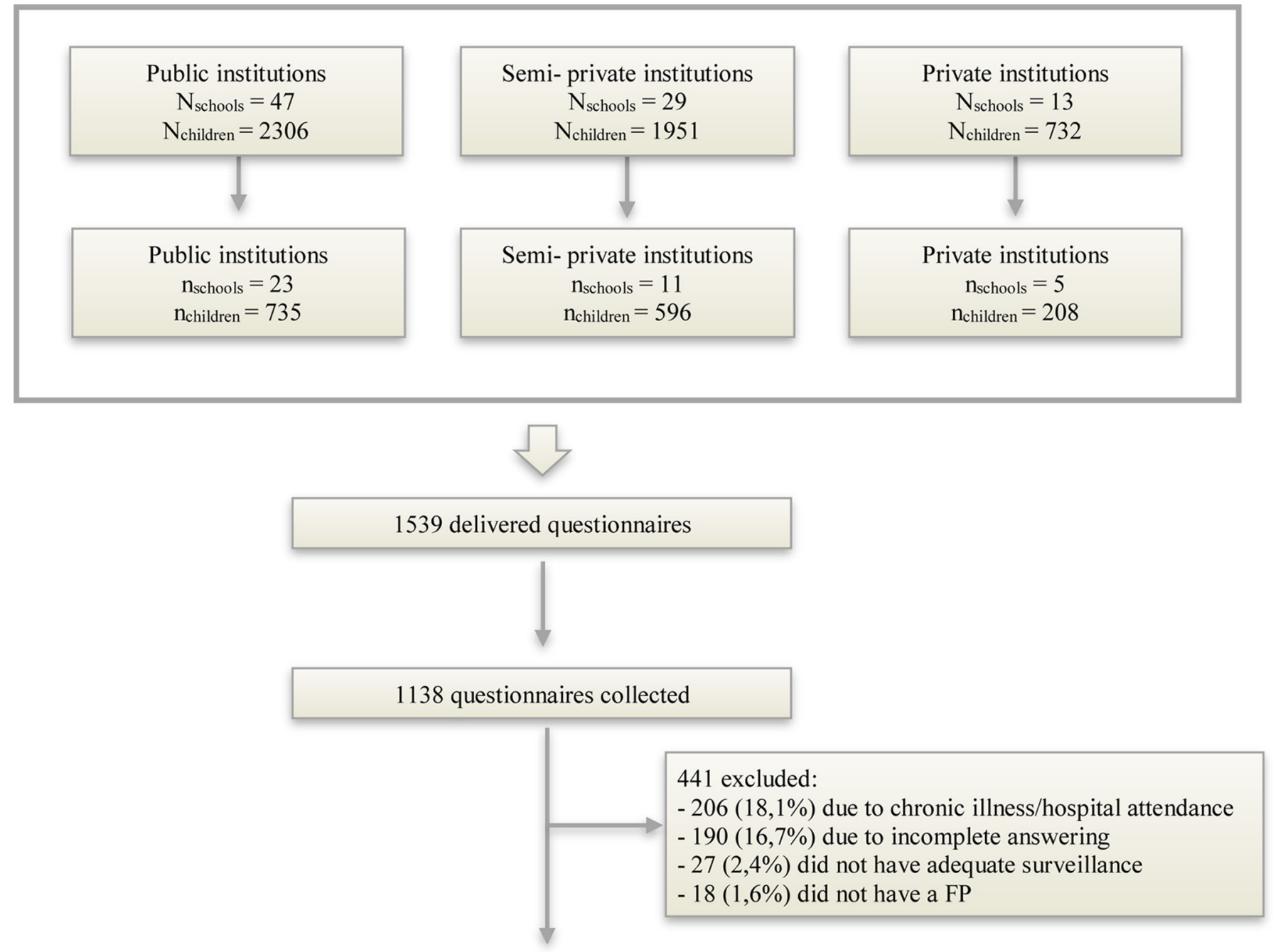

697 questionnaires considered for data analysis

Figure 1 Flow chart showing the sample selection. FP, family physician.

have access to private care without any insurance, paying the total costs of the care provided. ${ }^{45}$

The NHS is accessible to all residents in Portugal and provides primary and secondary healthcare. It is financed mainly through taxation and tends to be free of charge, but copayments that take into account citizens' social and economic background can be charged. However, there are certain types of appointments free of charge, regardless of individual income, such as medical appointments for those under the age of $18 .^{5}$

The National Programme for Child and Juvenile Health establishes 18 surveillance appointments provided by primary care at specific ages, 13 of them on the first 6 years of life. ${ }^{6}$ Additionally, there is a Portuguese National Vaccination Plan ${ }^{7}$ which is free of charge and only accessible through the primary care of NHS.

Portuguese primary healthcare physicians have a 4-year residency training which includes paediatrics rotation in secondary care and the normal surveillance of children included in the FP residency programme. ${ }^{8}$ This training enables FPs to monitor healthy children and identify any disorders that can be either treated in primary care or that require referral to paediatrics in secondary care.

In the Portuguese NHS, paediatricians work in secondary care, and although they are also qualified to follow healthy children, they mainly assume this role in the private sector.

There are no official data regarding the proportion of children followed simultaneously by FPs in the NHS and by paediatricians in the private sector, but it is clear from daily practice that this choice has been increasing in the past years, leading to duplicated care of healthy children.

According to the national health survey of $2005 / 2006$, $31.1 \%$ of children under fifteen are followed by paediatricians in the private sector. ${ }^{9}$ In 2016, in the county of Vila Nova de Famalicão, the proportion of children with adequate surveillance by FPs in the first year of life was $80 \%$ and $79.3 \%$ in the second year of life. ${ }^{10}$

The use of multiple care providers is associated with poor continuity of care and excess costs to the healthcare system. ${ }^{11}$ According to the behavioural model developed 
Table 1 Sociodemographic and household characteristics of the participants $(n=697)$

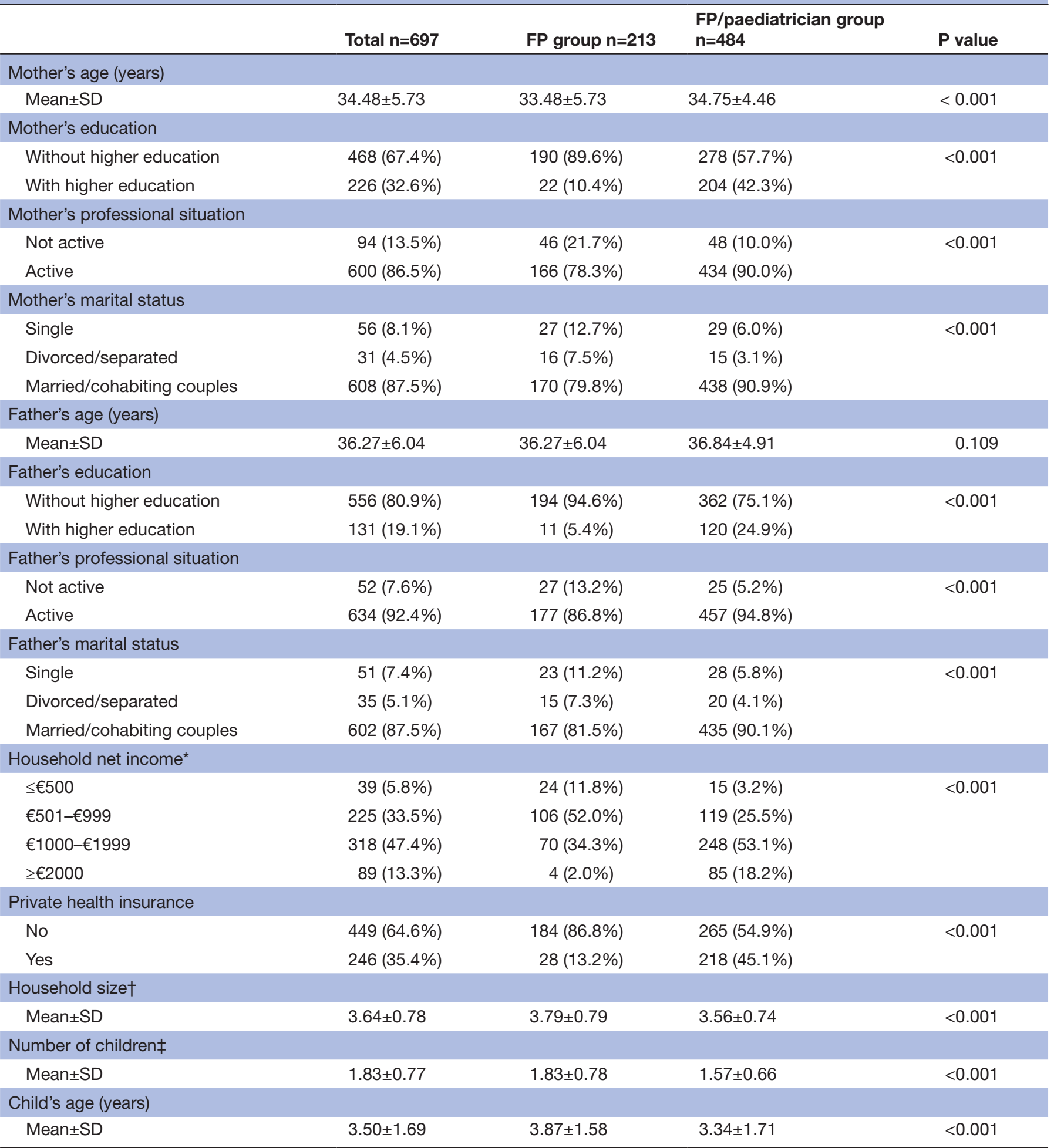

*€500 (£423; US\$562) corresponds to approximately one national minimum wage; $€ 1000=£ 847 /$ US $\$ 1123 ; € 2000=£ 1693 /$ US $\$ 2246$. †Number of people living in the same house. $\ddagger$ Total number of children of both parents. FP, family physician.

by Andersen ${ }^{12}$ the use of health services is determined by three elements: predisposing factors, enabling factors and need. ${ }^{13}$ Some studies have shown that parents with higher education level, higher incomes and active professional status are considered predisposing factors to seek healthcare services for their children. ${ }^{14-18}$

Therefore, the main objectives of our study consisted both in determining whether children attend the FP or 
Table 2 Poisson regression for determination of variables associated with FP and FP/paediatrician groups

\begin{tabular}{|c|c|c|}
\hline Independent variables & PR & $95 \% \mathrm{Cl}$ for $\mathrm{PR}$ \\
\hline Mother's age (years) & 1.02 & 1.00 to 1.03 \\
\hline \multicolumn{3}{|l|}{ Mother's education } \\
\hline Without higher education & 1 & - \\
\hline With higher education & 1.15 & 1.00 to 1.33 \\
\hline \multicolumn{3}{|l|}{ Mother's professional situation } \\
\hline Not active & 1 & - \\
\hline Active & 1.24 & 0.99 to 1.54 \\
\hline \multicolumn{3}{|l|}{ Father's education } \\
\hline Without higher education & 1 & - \\
\hline With higher education & 1.12 & 0.95 to 1.32 \\
\hline \multicolumn{3}{|l|}{ Father's professional situation } \\
\hline Not active & 1 & - \\
\hline Active & 1.28 & 0.96 to 1.70 \\
\hline \multicolumn{3}{|l|}{ Household net income* } \\
\hline$\leq € 500$ & 1.24 & 0.82 to 1.87 \\
\hline$€ 501-€ 999$ & 1.14 & 0.78 to 1.65 \\
\hline$€ 1000-€ 1999$ & 0.94 & 0.65 to 1.37 \\
\hline$\geq € 2000$ & 1 & - \\
\hline \multicolumn{3}{|l|}{ Private health insurance } \\
\hline No & 1 & - \\
\hline Yes & 1.30 & 1.15 to 1.46 \\
\hline Number of children† & 0.86 & 0.78 to 0.94 \\
\hline Child's age (years) & 0.95 & 0.91 to 0.98 \\
\hline
\end{tabular}

The FP group was considered as the reference group for the Poisson regression. The variables father's age and household size were not included as they were suspected to be highly correlated, contributing to model multicollinearity. The parents' marital status was not included due to lack of clinical relevance.

* $€ 500$ (£423; US\$562) corresponds to approximately one national minimum wage; $€ 1000=£ 847 / \$ 1123 ; € 2000=£ 1693 / U S \$ 2246$.

†Total number of children of both parents.

FP, family physician; PR, prevalence ratio.

the $\mathrm{FP}$ /paediatrician in their surveillance appointments, and in ascertaining the variables associated with the parents' choice between the two physicians.

This study has particular significance because, to the best of our knowledge, it is the first study to be accomplished on this matter.

\section{METHODS}

\section{Study design}

Since this was a cross-sectional study, in order to determine the factors associated with parental choices in the medical care of their children, a questionnaire was designed by the researchers. This questionnaire is enclosed in the online supplementary annex along with the protocol.

\section{Setting and study size}

The study population comprised all children up to 6 years of age, including those enrolled in public, semiprivate and private kindergartens in the city of Vila Nova de Famalicão, a county in the north of Portugal.

According to national statistics, in September 2015 there were 4989 children enrolled in the kindergartens in the city of Vila Nova de Famalicão. ${ }^{19}{ }^{20}$ We determined a minimum sample size of 536 valid questionnaires using OpenEpi, considering a $50 \%$ proportion of children being attended simultaneously by FPs and paediatricians, a CI of $95 \%$ and a design effect of 1.5 . A conservative approach, using a $50 \%$ prevalence, was considered because no evidence was available on the proportion of children simultaneously attended by FPs and paediatricians, at a national level. We considered that the number of delivered questionnaires should be three times greater in order to deal with non-delivered questionnaires and the exclusion criteria which could not be anticipated. At the time, this county comprised 89 kindergartens, 47 of which were public, 29 semiprivate and 13 were private. ${ }^{21}$ We used a random sample that was stratified by school type-public, semiprivate or private. Strata weights were calculated using the number of students in each specific stratum and the total number of students in all schools. In each stratum, schools were considered as sampling units and were randomly chosen with selection probabilities proportional to the number of students. And again, in each stratum, the school selection process ended when the total number of children was superior to the determined sample size for each school type. Therefore, all the parents from the selected schools were invited to participate.

\section{Participants}

The parents of children from the selected kindergartens were personally invited to participate, and the purpose of the study was explained to them by the teachers who were previously trained by the researchers. The parents who accepted to participate signed an informed consent and received a questionnaire delivered by the preschool teachers between April and May 2016. Surveys were preferably answered at home by both parents. Anonymity and confidentiality of all the participants' data were maintained, as they placed the unidentified questionnaires in a sealed box. They were then collected by the researchers in June 2016.

We excluded the following children: those with chronic diseases followed by paediatricians in public hospitals, those up to 2 years of age who had a paediatrician but did not attend their services in the previous year and those older than 2 years who had not had an appointment in the two preceding years. We also excluded children who did not have an FP and those who had an FP but did not have adequate monitoring. Based on the National Programme for Child and Juvenile Health, ${ }^{6}$ children are expected to attend nine surveillance appointments during the first 2 years of life and once a year until the age 


\begin{tabular}{|c|c|c|c|c|}
\hline & \multicolumn{2}{|c|}{$\begin{array}{l}\text { Items about knowledge related to } \\
\text { the: }\end{array}$} & \multicolumn{2}{|c|}{$\begin{array}{l}\text { Items about accessibility related to } \\
\text { the: }\end{array}$} \\
\hline & Family physician & Paediatrician & Family physician & Paediatrician \\
\hline $\begin{array}{l}\text { Participants with family physician and } \\
\text { paediatrician }\end{array}$ & $3.85 \pm 0.87^{*}$ & $4.11 \pm 0.87^{\star}$ & $2.38 \pm 1.10^{\star}$ & $4.29 \pm 0.77^{*}$ \\
\hline$P$ value & $<0.001$ & $<0.001$ & $<0.001$ & $<0.001$ \\
\hline
\end{tabular}

${ }^{*}$ Mean \pm SD.

†Did not have a paediatrician.

of 6. Consequently, we established as inadequate surveillance attending less than $80 \%$ of the appointments for children up to 2 years old, and not having attended the FP in the two previous years for older children in primary care. Incomplete surveys (under $80 \%$ of answered questions) were not considered for data analysis.

\section{Variables and data-collection instrument}

The questionnaire consisted of two parts: the first comprised direct questions about the sociodemographic characteristics related to parents, children and the household. The second part consisted of statements about accessibility and knowledge regarding the FP and the paediatrician, to be rated according to a Likert scale. This scale includes five ordered response levels varying between 1 and 5, measuring either negative, neutral or positive response to a statement. There were three questions about the clinical knowledge and four about the accessibility regarding each physician. To evaluate knowledge, parents were asked about their perception of paediatric surveillance and acute/urgent disease management skills for both physicians. Accessibility was assessed with questions about appointment scheduling (urgent, monitoring and after work hours appointments) and the possibility to establish telephone contact with the physicians.

Content validity was tested with eligible patients, and minor modifications were implemented. Data obtained by this process were not included in data analysis.

We included 13 sociodemographic and household variables in the analyses: parents' age, education level; professional situation and marital status; household size and net income; number of children; child's age and health insurance situation. Additionally, two more variables, accessibility and clinical knowledge, related to the FP or paediatrician, were included.

\section{Statistical methods}

For statistical analysis, responders were divided into two groups: children who attended only the FP (FP group) and children who attended both the FP and the paediatrician ( $\mathrm{FP} /$ paediatrician group).

Categorical variables are described as frequencies and percentages, and continuous variables as means and SDs.

Differences between FP and FP/paediatrician groups' characteristics were tested using a $\chi^{2}$ test for categorical variables and a Student's t-test for independent samples. The multivariable Poisson regression model was used to test an association between sociodemographic/household variables and $\mathrm{FP}$ or $\mathrm{FP} /$ paediatrician groups. This model included as independent variables those that were clinically supported. The variables father's age and household size were not included as they were suspected to be highly correlated, which would lead to model multicollinearity.

Perceptions of accessibility and knowledge were compared between FP and $\mathrm{FP}$ /paediatrician groups using independent t-tests. Additionally, accessibility and knowledge about the FP and paediatrician were compared using a paired t-test, only for children who belonged to the $\mathrm{FP}$ /paediatrician group.

The sample was treated as complex, considering the processes of stratification and clustering, and using adequate weighting of cases for all statistical analysis.

The latter was performed with SPSS V.23.0, and an $\alpha=0.05$ was assumed.

\section{RESULTS}

A total of 697 questionnaires were considered for the analysis (figure 1), $213(30.6 \%)$ from the FP group and 484 (69.4\%) from the FP/paediatrician group. The global missing data were $1.2 \%$, and for each individual variable it was inferior to $3 \%$.

Table 1 summarises the sociodemographic and household characteristics of the participants in the study. We found that the differences between the two groups for all the variables were statistically significant, except for the father's age $(\mathrm{P}=0.109)$. Higher education was more frequent in the $\mathrm{FP} /$ paediatrician group $(42.3 \%$ vs $10.4 \%$ for the mother, $\mathrm{P}<0.001$, and $24.9 \%$ vs $5.4 \%$ for the father, $\mathrm{P}<0.001)$. The active professional status was more frequent in the $\mathrm{FP} /$ paediatrician group when compared with the FP group (90\% vs $78.3 \%$ for the mother, $\mathrm{P}<0.001$, and $94.8 \%$ vs $86.8 \%$ for the father, $\mathrm{P}<0.001)$. Higher incomes were also more frequent in the paediatrician/FP group, with $71.3 \%$ having a monthly net income of $€ 1000$ (£847; US $\$ 2245$ ) or more, compared with only $36.3 \%$ in the FP group. Additionally, $45.1 \%$ of the children in the FP/ Paediatrician group and only $13.3 \%$ in the FP group had private health insurance $(\mathrm{P}<0.001)$. 
We adjusted a Poisson regression (table 2) considering as dependent variable attending an FP or attending an $\mathrm{FP} /$ paediatrician, and as independent variables all those presented in table 1 . We excluded the father's age and household size as they were suspected to be highly correlated, and the parents' marital status due to lack of clinical relevance. Variables such as mother's educational level and age, private health insurance, number of children and children's age remained statistically associated with attending both physicians, with a prevalence ratio (PR) of 1.02 for the mother's age (95\% CI 1.00 to 1.03), 1.15 for the mother's educational level (95\% CI 1.00 to $1.33), 1.30$ for having a private health insurance $(95 \% \mathrm{CI}$ 1.15 to 1.46$), 0.86$ for the number of children $(95 \% \mathrm{CI}$ 0.78 to 0.94 ) and 0.95 for the child's age (95\% CI 0.91 to 0.98). There was no significant association between the household income ( $\mathrm{PR}=1.24$ (95\% CI 0.82 to 1.87 ) for incomes under $€ 500$; $\mathrm{PR}=1.14$ (95\% CI 0.78 to 1.65 ) for incomes between $€ 501$ and $€ 999$; $P R=0.94$ (95\% CI 0.65 to 1.37 ) for incomes between $€ 1000$ and $€ 1999$ ), the mother's professional situation $(\mathrm{PR}=1.24,95 \% \mathrm{CI} 0.99$ to 1.54$)$, the father's educational level $(\mathrm{PR}=1.12,95 \% \mathrm{CI}$ 0.95 to 1.32$)$, the father's professional situation $(\mathrm{PR}=1.28$, $95 \%$ CI 0.96 to 1.70 ) and the outcome.

Regarding the parents' perception about accessibility and clinical knowledge of the physicians, we found statistical differences between the two groups (table 3). The FP group rated the FP with a higher accessibility and knowledge mean score comparing with $\mathrm{FP}$ / paediatrician group (2.91 vs $2.38, \mathrm{P}<0.001$, and 4.11 vs $3.85, \mathrm{P}<0.001$ ). In the $\mathrm{FP} /$ paediatrician group, the mean score of accessibility and knowledge was significantly higher for the paediatrician compared with the FP ( 4.29 vs $2.53, \mathrm{P}<0.001$, and 4.11 vs $3.85, \mathrm{P}<0.001$ ).

\section{DISCUSSION}

In our study, only about $30 \%$ of the children attended the FP exclusively for surveillance appointments, and $70 \%$ of the sample attended both the FP and the paediatrician.

We found that the mother's age and her educational level, private health insurance, number of children and the child's age were associated with attending both the FP and the paediatrician. The variable with higher impact in the parents' choice was having a private health insurance (PR=1.30, 95\% CI 1.15 to 1.46 ). Both mother's age and her educational level were statistically associated with attending both physicians. However, father's age and his educational level were not associated with the parents' choice. This could be explained by social and cultural influences in Portugal where the mother is still considered as the centre of nurture and care in the family life. Additionally, both the number of children and the child's age were also associated with the parents' choice. We think this may be explained by a higher experience as children grow older, and the parent's awareness about the child's health. Furthermore, economic reasons may influence this choice as the number of children grows.
Our results are supported by the Robert Graham Center study ${ }^{1}$ findings: the proportion of children attending the paediatrician decreases as children grow older, and children with private health insurance are more likely to attend the paediatrician. Regarding the parents' perception of accessibility and the clinical knowledge of the FP and the paediatrician, we found statistical differences between the two groups. Parents who attended both physicians rated the FP with lower accessibility and knowledge than those who consulted only the FP.

\section{Strengths and limitations}

To the best of our knowledge, there are no previous studies available regarding the factors associated with parents' choice in the medical care of their children, so this is the first one addressing this important subject. Other strengths of our study are an adequate sampling, taking into consideration the three existing school types: public, semiprivate and private.

The main limitation found by the researchers was that only the variables associated with attending the FP or the paediatrician were determined. The causes of this outcome could not be determined as causality cannot be evaluated with this study design.

Conclusions and implications for future research and practice We identified variables associated with the parents' choice in the medical care of their children and having private health insurance were the most relevant ones.

Our data show that FPs still play an important role in children's follow-up, even though approximately $70 \%$ of our sample simultaneously attended a paediatrician. This can translate into a duplication of care and costs.

Unlike paediatricians, the role of FPs is still unclear to most parents since they rated the FP with a lower average clinical knowledge than the paediatrician. However, FPs and paediatricians are equally qualified to provide medical care to children without chronic diseases, with the advantage that costs associated with the same surveillance appointments are lower when carried out in primary healthcare. ${ }^{22-25}$ Moreover, we believe that these facts should be advertised and included in the healthcare promotion and education provided to parents and the general population.

The conclusions of our study may be valid in other settings: the population is highly comprehensive since it includes children from different social strata and ages.

Additional investigation is relevant to understand if children's medical care provided simultaneously by a paediatrician and an FP is associated with health benefits and higher public health costs when compared with medical care provided exclusively by the FP.

\section{Author affiliations}

${ }^{1}$ Family Health Unit Ribeirão, Northern Regional Health Administration, Vila Nova de Famalicão, Portugal

${ }^{2}$ Family Health Unit Terras do Ave, Northern Regional Health Administration, Vila Nova de Famalicão, Portugal 
${ }^{3}$ Personalized Health Care Unit Chaves A, Northern Regional Health Administration, Chaves, Portugal

${ }^{4}$ Family Health Unit Serzedelo, Family Health Unit Ribeirão, Guimarães, Portugal ${ }^{5}$ Western Oporto Public Health Unit, Northern Regional Health Administration, Porto, Portugal

${ }^{6}$ EPIUnit -The Epidemiology Research Unit, University of Porto, Porto, Portugal

Acknowledgements The authors would like to thank the City Council of Vila Nova de Famalicão, and acknowledge the contribution of the institutions that participated in the study as well as the willingness of all the parents who kindly answered the questionnaire.

Collaborators Carolina Gonçalves, Lucélia Campinho, Susana Vilar Santos, Vasco Duarte and Juliana Couto were collaborators in the study. Carolina Gonçalves contributed to the study design. Lucélia Campinho, Susana Vilar Santos and Vasco Duarte contributed both to questionnaire validation and data collection. Juliana Couto corrected the final manuscript.

Contributors SR, SVR, JOL, AC, RT and JF-M designed the study concept, wrote the protocol and collected the data. All authors contributed to the questionnaire validation and data collection. SR and JF-M conducted the analyses. All authors helped to draft the manuscript, read and approve the final manuscript. All authors had full access to all data (including statistical reports and tables) in the study and can take responsibility for the integrity of the data and the accuracy of the data analysis. SR and JF-M are the study guarantors.

Funding This research received no specific grant from any funding agency in the public, commercial or not-for-profit sectors.

Competing interests None declared.

Patient consent Detail has been removed from this case description/these case descriptions to ensure anonymity. The editors and reviewers have seen the detailed information available and are satisfied that the information backs up the case the authors are making.

Ethics approval Ethical approval was obtained from the City Council of Vila Nova de Famalicão (Aproximar programme) regarding public institutions and from the directors of the private and semi-private kindergartens.

Provenance and peer review Not commissioned; externally peer reviewed.

Data sharing statement The questionnaire is available on request to the corresponding author.

Open Access This is an Open Access article distributed in accordance with the Creative Commons Attribution Non Commercial (CC BY-NC 4.0) license, which permits others to distribute, remix, adapt, build upon this work non-commercially, and license their derivative works on different terms, provided the original work is properly cited and the use is non-commercial. See: http://creativecommons.org/ licenses/by-nc/4.0/

(c) Article author(s) (or their employer(s) unless otherwise stated in the text of the article) 2018. All rights reserved. No commercial use is permitted unless otherwise expressly granted.

\section{REFERENCES}

1. Phillips RL, Dodoo MS, McCann JL, et al. Report to the Task Force on the Care of Children by Family Physicians. Washington, DC: The Robert Graham Center for Policy Studies in Family Medicine and Primary Care in collaboration with the American Academy of Pediatrics Center for Child Health Research, 2005.

2. Bazemore AW, Makaroff LA, Puffer JC, et al. Declining numbers of family physicians are caring for children. J Am Board Fam Med 2012;25:139-40.
3. Makaroff LA, Xierali IM, Petterson SM, et al. Factors influencing family physicians' contribution to the child health care workforce. Ann Fam Med 2014;12:427-31.

4. Jakubowski E, Busse R. Health Care Systems in the EU: a comparative study. Luxemburg: European Parliament, 1998.

5. Barros PP, Machado SR, Simões JA. Portugal. Health system review. Health Syst Transit 2011;13:1-156.

6. Direção Geral de Saúde. Programa Nacional de Saúde Infantil e Juvenil. Portugal, Lis- bon: Direção Geral de Saúde, 2013.

7. Direção Geral de Saúde. Programa Nacional de Vacinação 2017. Portugal, Lisbon: Direção Geral de Saúde, 2017.

8. Ministério da Saúde. Diário da República, 1.a série, N.o $36-20$ de fevereiro de, 2015.

9. Entidade Reguladora da Saúde. Caracterização do Acesso dos Utentes a Cuidados de Saúde Infantil e Juvenil e de Pediatria: Março, 2011.

10. SIARS platform. P01.02.02.R01. Relatório de Indicadores ACeS no Período em análise. (accessed 3 jul 2017).

11. Macpherson AK, Kramer MS, Ducharme FM, et al. Doctor shopping before and after a visit to a paediatric emergency department. Paediatr Child Health 2001;6:341-6.

12. Andersen RM. Revisiting the behavioral model and access to medical care: does it matter? J Health Soc Behav 1995;36:1-10.

13. Andersen R, Davidson P. Improving access to care in America: individual and contextual indicators. In: Andersen RM, Rice TH, Kominski EF, eds. Changing the U.S. health care system: key issues in health services, policy, and management. San Francisco, CA: Jossey-Bass, 2001:3-30.

14. Burokien囚 S, Raistenskis J, Burokait $\mathbb{E}$, et al. Factors determining parents' decisions to bring their children to the pediatric emergency department for a minor illness. Med Sci Monit 2017;23:4141-8.

15. Abdulkadir M, Ibraheem R, Johnson W. Sociodemographic and clinical determinants of time to care-seeking among febrile children under-five in North-Central Nigeria. Oman Med J 2015;30:331-5.

16. Wysocki T, Gavin L. Psychometric properties of a new measure of fathers' involvement in the management of pediatric chronic diseases. J Pediatr Psychol 2004;29:231-40.

17. Blumberg SJ, Halfon N, Olson LM. The national survey of early childhood health. Pediatrics 2004;113:1899-906.

18. Abdulkadir MB, Abdulkadir ZA. A cross-sectional survey of parental care-seeking behavior for febrile illness among under-five children in Nigeria. Alexandria Journal of Medicine 2017;53:85-91.

19. Gabinete de Estratégia e Planeamento. Carta Social. Resposta Social: Creche - Equipamentos existentes no Distrito de Braga, Concelho de Vila Nova de Famalicão. http://www.cartasocial.pt/ resultados_pesquisageral.php?filtrar=hidden\&cod_distrito $=03 \&$ cod concelho $=12 \&$ cod freguesia $=0 \&$ cod area $=11 \&$ cod valencia $=1103 \&$ nome $=\&$ localpostal=\&tem Cert=false $($ accessed 5 Sep 2015).

20. Direção Geral de Estatísticas da Educação e Ciência. Regiões em Números 2013/2014, Volume I: Norte. Posrtugal, Lisbon, 2015:197-200.

21. Câmara Municipal de Vila Nova de Famalicão. Jardins-de-infância. http://www.cm-vnfamalicao.pt/_jardins_de_infancia_2 (accessed 5 Sep 2015).

22. Starfield B, Shi L, Macinko J. Contribution of Primary Care to Health Systems and Health. Milbank Q 2005;83:457-502.

23. Franks P, Fiscella K. Primary care physicians and specialists as personal physicians. Health care expenditures and mortality experience. The Journal of Family Practice 1998;47:105-9.

24. Mark DH, Gottlieb MS, Zellner BB, et al. Medicare costs in urban areas and the supply of primary care physicians. The Journal of Family Practice 1996;43:33-9.

25. Doescher MP, Franks P, Saver BG. Is family care associated with reduced health care expenditures? The Journal of Famiy Practice 1999;48:608-14. 